\title{
Correction to: Pediatric musculoskeletal pathologies: are there differences in triage of diagnoses and preferences for communication between radiology and orthopedics?
}

\section{Syed H. Hussaini ${ }^{1} \cdot$ Marian Gaballah $^{1} \cdot$ Soroush Baghdadi ${ }^{2} \cdot$ Alexandre Arkader $^{2,3} \cdot$ Brendan A. Williams $^{2,3}$.} Raymond W. Sze ${ }^{1,3} \cdot$ Jie C. Nguyen ${ }^{1,3}$

Published online: 12 January 2022

(c) ISS 2022

\section{Correction to: Skeletal Radiology}

https://doi.org/10.1007/s00256-021-03961-y

The correct name should be Marian Gaballah instead of Marian Gabellah.

The original article has been corrected.

Publisher's note Springer Nature remains neutral with regard to jurisdictional claims in published maps and institutional affiliations.

The original article can be found online at https://doi.org/10.1007/ s00256-021-03961-y.

Jie C. Nguyen

nguyenj6@email.chop.edu

1 Department of Radiology, Children's Hospital of Philadelphia, 3401 Civic Center Blvd, Philadelphia, PA 19104, USA

2 Divison of Orthopedic Surgery, Children's Hospital of Philadelphia, Philadelphia, PA, USA

3 University of Pennsylvania School of Medicine, Philadelphia, PA, USA 